\title{
Protracted 'Pro-Addictive' Phenotype Produced in Mice by Pre-Adolescent Phenylpropanolamine
}

\author{
Karen K Szumlinski*,', Andrew Liu', Jeffery H Penzner' and Kevin D Lominac' \\ 'Department of Psychology and the Neuroscience Research Institute, University of California at Santa Barbara, Santa Barbara, CA, USA
}

\begin{abstract}
For decades, the sympathomimetic phenylpropanolamine (PPA; \pm -norepinephrine) was an active ingredient found in popular children's over-the-counter (OTC) cold, cough, and allergy medications. To examine the possibility that pre-adolescent PPA exposure may induce neuroadaptations that influence behavioral and neurochemical responding to cocaine, C57BL/6) mice were pretreated with PPA (0$40 \mathrm{mg} / \mathrm{kg}$ ) during postnatal days $21-3 \mathrm{l}$. The behavioral and neurochemical responses to acute and repeated cocaine $(4 \times 15 \mathrm{mg} / \mathrm{kg})$ were then assessed in adulthood when the mice were 10 weeks of age. Whereas pre-adolescent PPA exposure did not influence the acute locomotor response to $15 \mathrm{mg} / \mathrm{kg}$ cocaine, PPA pre-exposure dose-dependently enhanced the expression of cocaine-induced place conditioning, reduced the expression of locomotor sensitization, but did not influence cocaine-induced stereotypy. Pre-adolescent PPA exposure completely prevented the capacity of cocaine to elevate extracellular levels of catecholamines in the nucleus accumbens, but facilitated the development of cocaine-induced glutamate sensitization. Neither acute nor repeated cocaine altered extracellular GABA levels in the accumbens of control mice; however, $15 \mathrm{mg} / \mathrm{kg}$ cocaine lowered GABA levels by approximately $40 \%$ in PPA pretreated mice and this effect showed tolerance with repeated cocaine administration. These data provide the first evidence that early exposure to an OTC compound produces protracted effects upon cocaine-induced changes in nucleus accumbens neurotransmission that may contribute to a 'pro-addictive' phenotype in adulthood.

Neuropsychopharmacology (2007) 32, |760-1773; doi: I0.1038/sj.npp. I 30 I 306; published online 24 January 2007
\end{abstract}

Keywords: phenylpropanolamine; sensitization; reward; pre-adolescence; cocaine; nucleus accumbens

\section{INTRODUCTION}

The marked increase in the prescription of psychotropic drugs to children (Zito et al, 2000) has sparked a considerable amount of research concerning the enduring psychobiological effects of pre-adolescent (juvenile) prescription drug exposure, particularly as they relate to the behavioral sensitivity to illicit drugs in adulthood (cf., Carlezon and Konradi, 2004). However, no study to date has examined the possibility that juvenile exposure to a psychotropic over-the-counter (OTC) medication may alter the function of brain reward circuits and influence subsequent susceptibility to addiction-related behaviors. Phenylpropanolamine (PPA; \pm -norephedrine) is a nonselective adrenergic receptor agonist and norepinephrine reuptake inhibitor (Hoffman, 2001) that was widely available for decades in popular children's OTC cold, cough, and allergy medications (eg, Alka-Seltzer ${ }^{\mathbb{R}}$ Plus

*Correspondence: Dr KK Szumlinski, Department of Psychology, University of California at Santa Barbara, Santa Barbara, CA 931069660, USA, Tel: + I 805893 6I24, Fax: + I 805893 4303,

E-mail: szumlinski@psych.ucsb.edu

Received 26 April 2006; revised 10 November 2006; accepted 14 November 2006
Children's Cold Elixer and Orange, Cherry, Berry, and Yellow Triaminic ${ }^{\circledR}$ 3D preparations). Moreover, PPA is a major metabolite of methylphenidate (Patrick et al, 1981), the most highly prescribed psychomotor stimulant for the treatment of Attention-Deficit/Hyperactivity Disorder (eg, Zito et al, 2000). Despite its prevalence and sympathomimetic profile, the biopsychological effects of PPA have received very little experimental attention. Whereas PPA does not elicit locomotor hyperactivity in rats or maintain self-administration behavior in monkeys trained to selfadministered cocaine (Eisenberg et al, 1987; Mittleman et al, 1993; Woolverton et al, 1986), it substitutes for amphetamine in rat self-administration studies (Wellman et al, 1989). Moreover, PPA substitutes for illicit psychomotor stimulants in drug discrimination studies employing both human and nonhuman primates, as well as rodents (Chait et al, 1988; Lee et al, 1989; Mariathasan and Stolerman, 1992; Woolverton et al, 1986).

As PPA and illicit stimulant drugs share subjective and reinforcing properties, we assessed the protracted effects of pre-adolescent exposure to PPA upon the behavioral and neurochemical responses to cocaine in adulthood. We found that the administration of PPA to juvenile mice elicits enduring alterations in nucleus accumbens (NAC) neurotransmission that may culminate in a 'pro-addictive' 
phenotype in later life, posing OTC sympathomimetic drug exposure as a potential early environmental factor that may contribute to addiction vulnerability.

\section{MATERIALS AND METHODS}

\section{Subjects}

C57BL/6J male and female mice were obtained from Jackson Laboratory (Bar Harbor, ME) and used to generate male and female pups for the present experiments. For each experiment, pups from three different litters were weaned on postnatal day (PND) 21 and housed in same-sex pairs in brown, clear standard polyethylene cages $(15 \mathrm{~cm}$ wide $\times 23 \mathrm{~cm}$ long $\times 16 \mathrm{~cm}$ high) with woodchip bedding, under a regular 12-h light cycle (lights on 0700 hours). Between PND 21 and 30, a time corresponding to preadolescence in rodents (Adriani et al, 2004; Cirulli and Laviola, 2000; Spear and Brake, 1983), pups were administered, once daily, intraperitoneal (i.p.) injection of either saline vehicle ( $\mathrm{vol}=0.01 \mathrm{ml} / \mathrm{g}$ ) or 5,10 , and $40 \mathrm{mg} / \mathrm{kg}$ PPA. These doses of PPA are in the range of those used previously to examine the behavioral or neurochemical effects of PPA in adult rodents (Eisenberg et al, 1987; Mariathasan and Stolerman, 1992; Mittleman et al, 1993; Rushing et al, 1993; McMahon and Wellman, 1996). As PPA is an anorectic (eg, Eisenberg et al, 1987; Mittleman et al, 1993; Wellman, 1990), body weight was recorded daily before each injection. All injections, behavioral and neurochemical testing occurred during the light phase of the circadian cycle, between 0900 and $1600 \mathrm{~h}$. Statistical analysis of the behavioral and neurochemical data revealed no main effects of, or interactions with, the sex factor. All experimental protocols were consistent with the guidelines of the NIH Guide for Care and Use of Laboratory Animals (NIH Publication No. 80-23, revised 1996) and approved by the Institutional Animal Care and Use Committee of the University of California, Santa Barbara, CA.

\section{PPA-Induced Changes in Locomotor Activity during PND 21-30}

To determine whether or not PPA induced a psychoactive effect in pups, the locomotor response to PPA $(0,5,10$, and $40 \mathrm{mg} / \mathrm{kg}$ ) was measured on injections 1,5 , and 10 of repeated treatment (PNDs 21, 25, and 30, respectively). Locomotor activity was monitored in a noncolony room containing eight Plexiglas activity chambers $(22 \times 43 \times 33 \mathrm{~cm})$ (Omnitech Electronics, Columbus, $\mathrm{OH})$. A series of 16 photobeams (eight on each horizontal axis) tabulated horizontal movements and estimated the total distance traveled by the pups (in $\mathrm{cm}$ ). These chambers were interfaced to a Digiscan monitor (Omnitech Electronics, Columbus, $\mathrm{OH}$ ) and an IBM PC computer provided automated recording of motor behavior. On injections 1, 5 , and 10 of repeated PPA administration, pups were weighed, injected i.p. with the appropriate pretreatment dose and placed immediately into the activity chambers for $2 \mathrm{~h}$. On the intervening days, mice were weighed, injected, and returned to their home cages. Following the last PPA injection, mice were left undisturbed in the colony room until they were 10 weeks of age. Sample sizes ranged from 16 to $18 /$ dose.

\section{Place Conditioning and Locomotor Activity}

At 10 weeks of age, the capacity of four i.p. injections of $15 \mathrm{mg} / \mathrm{kg}$ cocaine (Sigma-Aldrich, St Louis, MO) to induce place-conditioning and locomotor sensitization was assessed using a biased place conditioning procedure identical to that described previously for mice (Szumlinski et al, 2002, 2004a, 2005b). As also discussed previously (eg, Szumlinski et al, 2002), a biased place-conditioning procedure was used to reduce the probability of observing a ceiling effect upon approach behavior (Shimosato and Ohkuma, 2000). The apparatus employed in the present study enabled the assessment of three aspects of behavior: motor activity, anxiety, and cocaine-induced place conditioning. The apparatus was constructed of Plexiglas $(46 \mathrm{~cm}$ long $\times 24 \mathrm{~cm}$ high $\times 22 \mathrm{~cm}$ wide $)$ and consisted of two chambers that were divided into two distinct compartments by a removable divider. One compartment was painted black, contained corncob bedding and was covered by an opaque black lid; the other compartment was painted white, contained no bedding and was covered by a translucent white lid. The chambers were equipped with two photocells each, which were aligned with a 0.5 -inch unpainted strip that ran along each wall of the apparatus to allow detection of the animals. The photocells were interfaced with a digital analyzer (Med Associates Inc., St Albans, VT) and a PC-type computer which provided information automatically as to the time spent in each compartment of the chamber and the number of photocell beam breaks, the latter of which was used to index both spontaneous and cocaine-induced changes in locomotor activity (Lominac et al, 2005, 2006; Szumlinski et al, 2002, 2004a, 2005a-c).

Place conditioning proceeded in the following four sequential phases: preconditioning test 1 (Pre-Test1), preconditioning test 2 (Pre-Test2), conditioning, and postconditioning test (Post-Test). For all phases, mice were placed in the chambers for a total of $15 \mathrm{~min}$, once daily. Following Pre-Test1, in which animals had free access to both compartments of the place-conditioning chambers, the mice were then given a second Pre-Test. No injections were administered on either Pre-Test. As the place-conditioning apparatus is essentially a black-white shuttle box, the time spent in the white compartment during Pre-Test1 served to index basal anxiety (Belzung et al, 1987) and the total number of beam breaks during Pre-Test1 served to index spontaneous locomotion in response to a novel environment. The time spent in the nonpreferred compartment on the Pre-Test 2 served as the baseline to assess the effects of conditioning.

Conditioning was conducted over an 8-day period. Cocaine-paired groups received i.p. injections, on alternate days, with either saline $(0.01 \mathrm{ml} / \mathrm{g}$ body weight $)$ or cocaine (a generous gift from NIDA, Bethesda, MD) and were placed in their preferred chamber on saline days or the nonpreferred chamber on cocaine days. To assist in the interpretation of shifts in the time spent in the nonpreferred chamber exhibited by cocaine-paired animals (eg, habituation to the aversiveness of the nonpreferred compartment; 
Bardo and Bevins, 2000), control groups were included that received saline injections on each conditioning day. As per earlier cocaine studies (Szumlinski et al, 2002, 2004a), all cocaine/saline injections were administered in the experimental room and animals were placed in the place conditioning apparatus $5 \mathrm{~min}$ following injection. As described previously in other place-conditioning studies (Lominac et al, 2006; Szumlinski et al, 2002, 2004a, $2005 \mathrm{a}, \mathrm{c})$, locomotor activity was monitored during the first and last conditioning session when the mice were confined to the drug-paired compartment and the difference in druginduced locomotor activity was used to index the development of cocaine-induced locomotor sensitization.

The day following the last conditioning session, a PostTest was conducted. The Post-Test was identical to the PreTests in that no injections were administered and mice had free access to both compartments. The difference in the time spent in the drug-paired compartment between the Post-Test and Pre-Test2 (occupancy difference) served to index the effects of cocaine/saline on place conditioning. Samples sizes ranged from 7 to 9 mice/PPA dose.

\section{Cocaine-Induced Stereotypy}

In addition to a sensitization of horizontal locomotion, the repeated administration of psychomotor stimulant drugs, such as cocaine, can induce a sensitization of intensely focused, stereotyped behaviors in rodents (including grooming, rearing, and sniffing) that can interfere with the expression of horizontal locomotion (eg, Kuczenski et al, 1991). Moreover, the expression of both stimulantinduced locomotion and stereotypy can become conditioned to the environment in which the drug is administered with repeated drug administration (Badiani et al, 2000; Badiani and Robinson, 2004; Browman et al, 1998; Pert et al, 1990; Robinson et al, 1998; Szumlinski et al, 1997). Thus, to determine whether or not PPA pretreatment altered the expression of cocaine-induced stereotypy and to assess the potential role for conditioned factors in mediating the observed effects of PPA pretreatment upon cocaineinduced locomotor sensitization, groups of mice were pretreated with either saline control or $40 \mathrm{mg} / \mathrm{kg}$ PPA during PNDs 21-30. At 10 weeks of age, mice were assigned to receive either three injections of saline or three injections of $15 \mathrm{mg} / \mathrm{kg}$ cocaine. As per the experiments above, these injections were administered every other day, but in this experiment, mice were returned immediately to their home cage following injection. On the fourth injection, mice were transported to a noncolony room, all injected with $15 \mathrm{mg} / \mathrm{kg}$ cocaine, and placed immediately into activity chambers $(22 \mathrm{~cm}$ long $\times 24 \mathrm{~cm}$ high $\times 22 \mathrm{~cm}$ wide $)$. The total distance traveled by the mice was recorded for $2 \mathrm{~h}$ using two digital video cameras, interfaced with a PC-type computer loaded with Any-MAZE software (Stoelting Company, Wood Dale, IL) and video recordings were later scored for the expression of stereotypy by an experimenter blind to the pretreatment of the animals. As conducted previously (Szumlinski et al, 2000b), stereotypy was scored for $30 \mathrm{~s}$, in $10 \mathrm{~min}$ bins, using the following rating scale: $0=$ asleep; $1=$ awake but still; 2 =grooming or mild licking; $3=$ continuous, exploratory locomotion along the horizontal plane for the entire $30 \mathrm{~s}$ without rearing; $4=$ continuous, exploratory locomotion along the horizontal plane for the entire $30 \mathrm{~s}$ with rearing; $5=$ bouts of locomotion along the horizontal plane/'darting'without rearing or sniffing; $6=$ darting with bouts of rearing or sniffing; $7=$ continuous sniffing for $30 \mathrm{~s}$ without horizontal locomotion or rearing; $8=$ continuous sniffing for $30 \mathrm{~s}$ while rearing; $9=$ patterned sniffing or head-bobbing in a fixed location for less than $30 \mathrm{~s} ; 10=$ patterned sniffing or head-bobbing in a fixed location for the entire $30 \mathrm{~s} ; 11=$ continuous gnawing or focused grooming; $12=$ bizarre dyskinetic movements or seizures. Samples sizes $=7-8$ /group.

\section{Intracranial Surgery and In Vivo Microdialysis}

To relate the cocaine behavioral phenotype of the mice to cocaine-induced changes in neurotransmitters implicated in drug reward and psychomotor activation, in vivo microdialysis was conducted in the NAC of saline- and PPApretreated mice (PNDs 21-31), when the mice were 10 weeks of age. The $40 \mathrm{mg} / \mathrm{kg}$ PPA dose was selected for this experiment as it produced the largest effect upon cocaineinduced changes in behavior (Figure 2). At 9 weeks of age, mice were anesthetized under $4 \%$ isoflurane and were implanted bilaterally with a 20-gauge stainless-steel guide cannula (10 $\mathrm{mm}$ long) aimed above the NAC and the guide cannulae were fixed to the skull using dental resin as described previously (Lominac et al, 2005, 2006; Szumlinski et al, 2004a, 2005b, c). Following 1 week recovery, in vivo microdialysis was conducted. The procedures for probe construction and microdialysis were identical to those employed in previous studies of mice (Lominac et al, 2005, 2006; Szumlinski et al, 2004a, 2005b, c). Baseline dialysate was collected in 20 -min fractions into $10 \mu \mathrm{l}$ of a preservative solution for $1 \mathrm{~h}$, and then animals were administered $15 \mathrm{mg} /$ $\mathrm{kg}$ cocaine i.p. and dialysate collection continued for $3 \mathrm{~h}$. Mice were returned to the colony room and received two more injections of $15 \mathrm{mg} / \mathrm{kg}$ cocaine, every other day, in a manner consistent with the injection regimen employed in the behavioral study. The morning of the fourth cocaine injection, the microdialysis procedures were repeated, with the exception that a new probe was inserted unilaterally on the opposite side of the head. Upon completion of the second session, mice were overdosed with pentobarbital, perfused with saline and then a $4 \%$ paraformaldehyde solution. Their brains were extracted, sliced along the coronal plane (50 $\mu \mathrm{m}$ thick) and stained with Cresyl violet for histological examination of probe placement. Only dialysate from mice with probe placements within the shell region of the NAC were analyzed for neurotransmitter content. Sample sizes ranged from 6 to 8/group.

\section{HPLC Analysis of Monoamines and Amino Acids}

The procedures and equipment for the high-pressure liquid chromatography (HPLC) analysis of dialysate samples were identical to those described recently (Lominac et al, 2006). The HPLC system consisted of a Coularray detector, a Model 542 autosampler and two Model 582 solvent delivery systems (ESA Inc., Bedford, MA), which enabled the sequential detection of monoamines and amino acids. For monoamines, the MD-TM mobile phase was employed (ESA Inc.), and neurotransmitters were separated using a 
MD-150 $\times 3.2$ column $(15 \mathrm{~cm}$; ESA Inc. $)$ An ESA 5014B analytical cell with two electrodes was used for the electrochemical detection of monoamines - the reduction analytical electrode $(\mathrm{E} 1,-150 \mathrm{mV})$, and an oxidation analytical electrode $(\mathrm{E} 2,+220 \mathrm{mV})$. For amino acids, the mobile phase consisted of $100 \mathrm{mM} \mathrm{NaH}_{2} \mathrm{PO}_{4}, 22 \%$ methanol $(\mathrm{v} / \mathrm{v}), 3.5 \%$ acetonitrile $(\mathrm{v} / \mathrm{v}), \mathrm{pH} 6.75$, and were separated using a CAPCELL PAK C18 mg column $(5 \mathrm{~cm}$; Shiseido Company Ltd, Tokyo, Japan). An ESA 5011A analytical cell with two electrodes was used for the electrochemical detection of amino acids, following precolumn derivatization with $o$-phthalaldehyde using the autosampler. The electrodes were set to +150 and $+550 \mathrm{mV}$ for oxidation. Neurotransmitter content in each sample was analyzed by peak height, and was compared with external standard curves (one for each neurotransmitter) for quantification using ESA Coularray for Windows software. Under our conditions, the monoamines norepinephrine, dopamine and serotonin eluted at $3.1,5.2$, and $11.5 \mathrm{~min}$, respectively, whereas the amino acids glutamate and GABA eluted at 2.1 and $14.9 \mathrm{~min}$, respectively.

\section{Detection and Quantitation of Phenylpropanolamine in Plasma by LC/MS}

To determine the pharmacokinetics of PPA in pre-adolescent mice, mice were injected with $40 \mathrm{mg} / \mathrm{kg}$ PPA on PND 21 and trunk blood was sampled at 15, 30, 90, and $180 \mathrm{~min}$ following drug injection. The samples were centrifuged and the plasma frozen at $-80^{\circ} \mathrm{C}$ until shipped for liquid chromatography-mass spectrometry analysis by National Medical Services (NMS) Laboraties (Willow Grove, PA). An internal standard (D3-ephedrine) was added to $0.5 \mathrm{ml}$ of sample followed by dilution with water and buffering to $\mathrm{pH}$ 6.0 with phosphate buffer. Samples were extracted using a solid-phase extraction column (Varian Certified ${ }^{\mathbb{R}}$ ) and with $2 \%$ ammonium hydroxide in methanol as the final elution solvent. The elution solvent was evaporated to dryness and reconstituted with mobile phase. Samples were analyzed using a Micromass Platform II LC/MS with electrospray ionization, and a Hewlett Packard 1100 series HPLC with a Zorbax ${ }^{\circledR}$ SB-Phenyl $4.6 \mathrm{~mm}$ ID $\times 75 \mathrm{~mm}, 3.5 \mu \mathrm{m}$ analytical column. A four-component gradient mobile phase was used starting with a high concentration of aqueous and transitioning to an organic (methanol)-rich mixture. Two ions were monitored for both analyte (152 and 137) and internal standard (151 and 169) to verify identification. Quantitations were performed using second-order, $1 / x$ weighted, regression analysis of the response ratio of 152/151 vs concentration. Calibrators at concentrations of 5, 25, 50, 250, and $500 \mathrm{ng} / \mathrm{ml}$ ran along with Quality Control samples at target concentrations of 30 and $350 \mathrm{ng} / \mathrm{ml}$. Mouse plasma samples were diluted with blank matrix so that the calculated concentrations were within the range of calibration. Phenylpropanolamine and D3-ephedrine eluted at approximately 4.1 and $5.0 \mathrm{~min}$, respectively. Sample sizes ranged from 4 to 5 mice/time point.

\section{Statistical Analyses}

All data were analyzed by analyses of variance (ANOVA). As observed in an earlier study of behavioral and neurochemical effects of cocaine in mice (Szumlinski et al, 2000c, 2004a, 2005b), statistical analyses failed to detect any main effects of, or interactions with, the sex factor $(p>0.05)$. Thus, these data for male and female mice were collapsed for statistical analyses of PPA interactions with cocaine. Significant interactions were decomposed for simple effects, followed by LSD post hoc tests.

\section{RESULTS}

\section{PPA Pharmacokinetics when Administered during Pre-Adolescence}

To assess the pharmacokinetic profile of PPA in preadolescent mice, we injected PND 21 mice i.p. with the highest dose of PPA tested $(40 \mathrm{mg} / \mathrm{kg})$ and assessed for plasma levels at various times following injection. As depicted in Figure 1a, high levels of PPA were detected in plasma at $15 \mathrm{~min}$ post-injection and declined rapidly over the course of sampling in a manner independent of the sex of the animal (time effect, $\mathrm{F}(3,26)=11.21 ; p<0.0001$; sex effect, $p=0.33$; sex $\times$ time, $p=0.84$ ).

\section{PPA Inhibited Locomotor Activity during Pre-Adolescence}

PPA administration $(0-40 \mathrm{mg} / \mathrm{kg}$, i.p.) inhibited the locomotor activity exhibited by pre-adolescent mice and this effect was independent of PPA dose (Figure 1b). The PPAinduced locomotor inhibition lessened with repeated administration, the level of locomotor activity exhibited by PPA mice remained below that of saline controls throughout treatment (PPA effect: $\mathrm{F}(3,62)=19.21$, $p<0.0001$; PPA injection number effect: $\mathrm{F}(2,124)=34.36$, $p<0.0001 ; \mathrm{PPA} \times \mathrm{PPA}$ injection number: $\mathrm{F}(6,124)=1.76$, $p=0.11$ ).

PPA is an anorectic (Eisenberg et al, 1987; Mittleman et al, 1993; Wellman, 1990). Thus, we analyzed for the effects of PPA on weight gain in male and female pups during repeated treatment. As illustrated in Figure $1 \mathrm{c}$ and d, PPA treatment did not influence the gain in weight exhibited by either male or female pups during PNDs 21-30 in the place-conditioning study (sex effect: $\mathrm{F}(1,57)=$ $4.81, p=0.03$; PPA injection number effect: $\mathrm{F}(9,513)=385.65$, $p<0.0001$; PPA $\times$ sex: $p=0.60$; PPA $\times$ PPA injection number: $p=0.91$; PPA $\times \operatorname{sex} \times \mathrm{PPA}$ injection number: $p=0.59$ ).

\section{Protracted Effects of Pre-Adolescent PPA upon Cocaine-Induced Place Conditioning}

Pre-adolescent PPA administration produced a dosedependent enhancement in the expression of cocaineinduced place conditioning when mice were assessed in adulthood (Figure 2a). Whereas repeated saline administration did not elicit a change in the time spent in the nonpreferred compartment, the repeated pairing of $15 \mathrm{mg} /$ $\mathrm{kg}$ cocaine with the nonpreferred compartment of the placeconditioning apparatus elicited an increase in the time spent in that compartment in all pretreatment groups (cocaine effect: $\mathrm{F}(1,66)=24.4, p<0.0001)$. As illustrated in Figure $2 \mathrm{a}$, mice pretreated with $40 \mathrm{mg} / \mathrm{kg}$ PPA exhibited the greatest increase in the time spent in the cocaine-paired 

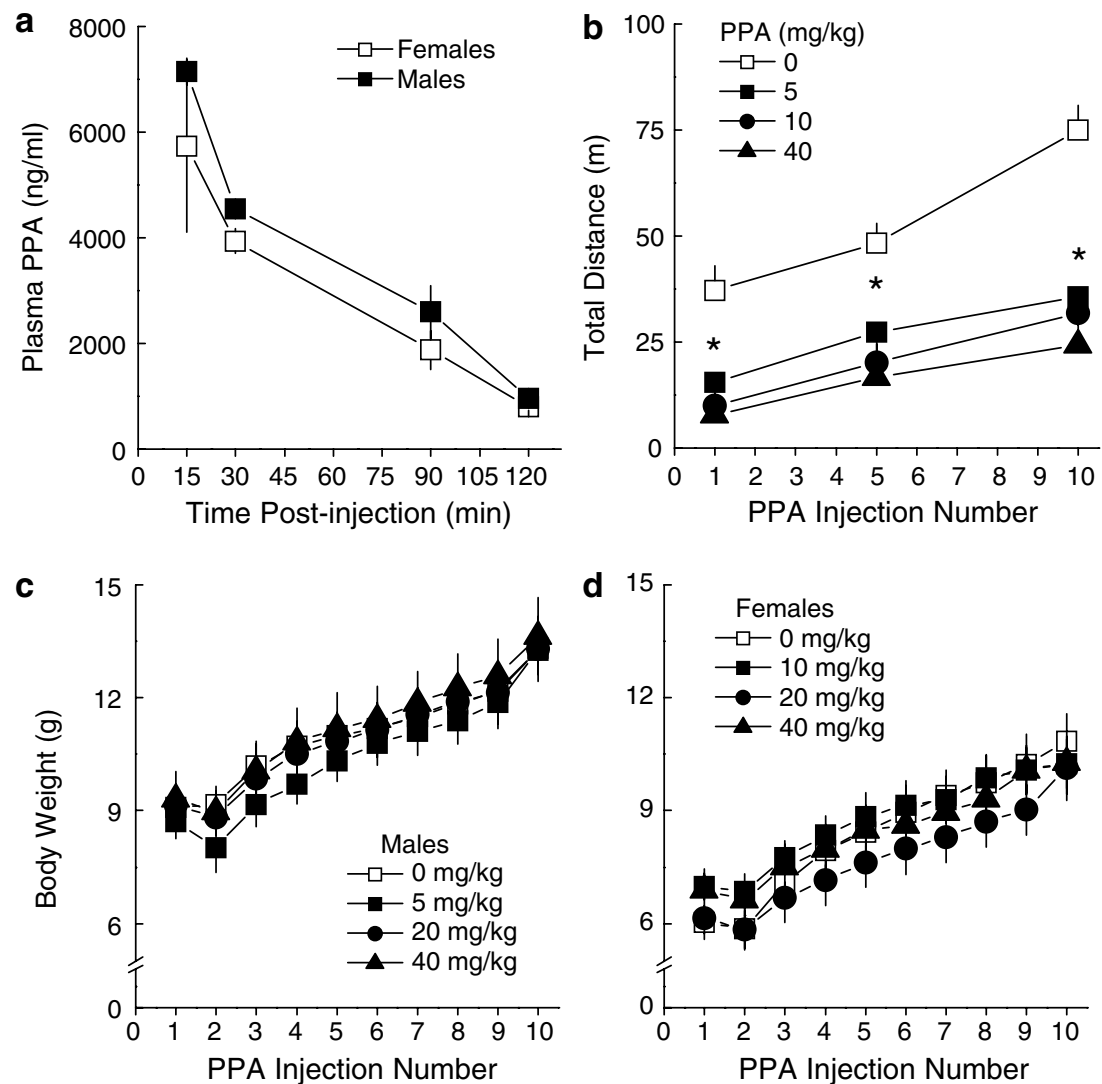

Figure I Effects of PPA administered during pre-adolescence. (a) The acute administration of $40 \mathrm{mg} / \mathrm{kg}$ PPA to PND 21 mice resulted in high plasma levels, which declined rapidly over sampling. The data represent the mean plasma concentrations of PPA \pm SEM of 2-5 mice. (b) The repeated administration of PPA (0-40 mg/ $/ \mathrm{kg}$, i.p.) administered during PNDs $21-30$ reduced locomotor activity in a dose-independent manner, compared to saline controls. The data represent the mean total distance traveled in a $2 \mathrm{~h}$ period \pm SEM of $16-18$ mice. Despite inducing psychomotor effects, pre-adolescent PPA administration did not influence the gain in bodyweight exhibited by either male (c) or female (d) pups. The data in (c) and (d) present the mean body weight (in g) \pm SEM of 7-9 mice. * $p<0.05$ vs SAL (0 mg/kg PPA).
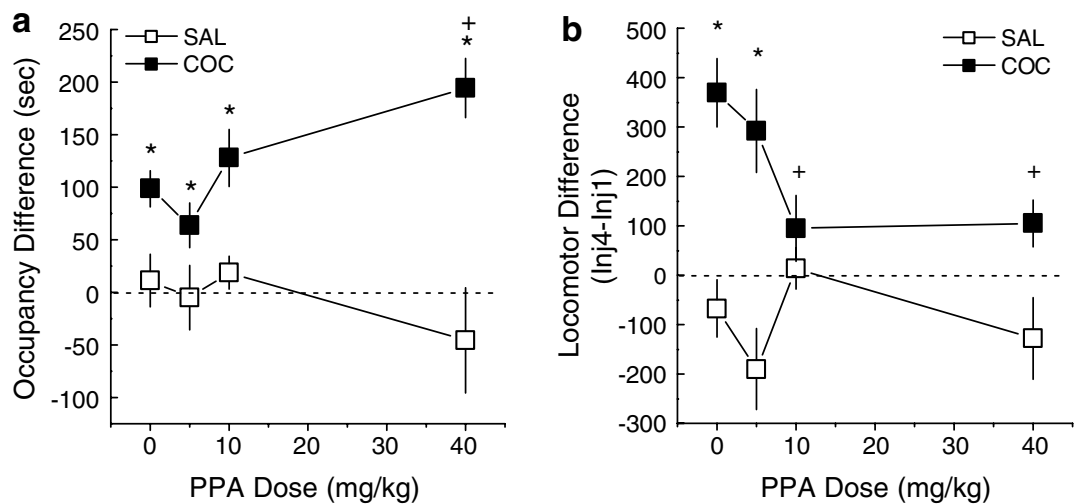

Figure 2 Enduring changes in cocaine behavioral responsiveness produced by pre-adolescent PPA. (a) Pre-adolescent PPA (0-40 mg/kg, i.p.) administered during PNDs $21-30$ dose-dependently enhanced the amount of time adult mice spent in an environment paired previously with $15 \mathrm{mg} / \mathrm{kg}$ cocaine The data represent the mean difference in time spent in the nonpreferred compartment of the place-conditioning apparatus on the Pre-Test vs the Post-Test \pm SEM of 6-8 animals. * $p<0.05$ vs SAL (conditioning); $+p<0.05$ vs 0 mg $/ \mathrm{kg}$ PPA. (b) Pre-adolescent PPA produced a dose-dependent reduction in the expression of cocaine-induced locomotor sensitization induced by four injections of $15 \mathrm{mg} / \mathrm{kg}$ cocaine. The data represent the mean difference in the number of photocell mean breaks between injections one and four of repeated cocaine/saline treatment \pm SEM of $6-8$ animals. * $p<0.05$ Inj 4 vs Injl (sensitization); $+p<0.05$ vs $0 \mathrm{mg} / \mathrm{kg}$ PPA).

compartment following conditioning, compared to the other groups tested (PPA pretreatment effect: $\mathrm{F}(3,66)=$ $1.42, \quad p=0.25 ; \quad \mathrm{PPA} \times$ cocaine: $\mathrm{F}(3,66)=4.82, p=0.008)$.
Moreover, planned comparison of the time spent in the cocaine-paired $v s$ the -unpaired compartment on the Post-Test revealed a significant place preference in the 
cocaine-conditioned mice pretreated with $40 \mathrm{mg} / \mathrm{kg} \mathrm{PPA}$, which was not apparent in the other pretreatment groups (Table 1). The protracted effects of pre-adolescent PPA administration upon cocaine-induced place conditioning did not relate to effects of pretreatment upon the time spent in the nonpreferred chamber at the outset of conditioning, as the four treatment groups did not differ significantly on this measure (Figure 3a) (PPA pretreatment effect: $\mathrm{F}(3,68)=0.84, p=0.48)$.

\section{Protracted Effects of Pre-Adolescent PPA upon Cocaine-Induced Locomotor Activity}

Pre-adolescent PPA administration did not influence the acute locomotor response to $15 \mathrm{mg} / \mathrm{kg}$ cocaine when the mice were assessed at 10 weeks of age (PPA pretreatment $\times$ cocaine: $\mathrm{F}(3,68)=1.32, p=0.26$; data not shown). However, pre-adolescent PPA administration dose-dependently blocked the development of cocaine-induced locomotor sensitization produced by the repeated administration of $15 \mathrm{mg} / \mathrm{kg}$ cocaine (Figure 2b). Whereas Repeated cocaine elicited a significant increase in the locomotor response to cocaine in mice pretreated with saline vehicle and $5 \mathrm{mg} / \mathrm{kg}$ PPA, whereas no such increase was apparent in mice pretreated with 10 or $40 \mathrm{mg} / \mathrm{kg}$ PPA (cocaine effect: $\mathrm{F}(1,68)=47.73, p<0.0001$; PPA pretreatment effect: $\mathrm{F}(3,68)=2.59, \quad p=0.06$; PPA pretreatment $\times$ cocaine: $\mathrm{F}(3,68)=5.11, p=0.003)$.

Table I Summary of the Mean Time Spent $( \pm$ SEM) in the Cocaine-Paired and the -Unpaired Compartments on the Post-Test

\begin{tabular}{lccccc}
\hline $\begin{array}{l}\text { Pretreatment } \\
(\mathbf{m g} / \mathbf{k g})\end{array}$ & \multicolumn{2}{c}{ SAL-conditioned } & & \multicolumn{2}{c}{ COC-conditioned } \\
\cline { 2 - 3 } \cline { 5 - 6 } PPA & Unpaired & Paired & & Unpaired & Paired \\
\hline 0 & $498.5 \pm 34.6$ & $401.4 \pm 34.6$ & & $431.7 \pm 15.4$ & $468.3 \pm 15.4$ \\
5 & $537.3 \pm 41.8$ & $362.8 \pm 41.8$ & & $521.0 \pm 37.6$ & $379.0 \pm 37.6$ \\
10 & $539.9 \pm 38.1$ & $360.1 \pm 38.1$ & & $438.8 \pm 20.0$ & $461.3 \pm 20.0$ \\
40 & $510.3 \pm 45.8$ & $389.8 \pm 45.8$ & & $379.9 \pm 40.1$ & $520.1 \pm 40.1 *$ \\
\hline
\end{tabular}

$\mathrm{SAL}=$ saline; $\mathrm{COC}=15 \mathrm{mg} / \mathrm{kg}$ cocaine. ${ }^{*} p<0.05$ vs unpaired, indicating a place preference.
The protracted effects of pre-adolescent PPA administration upon cocaine-induced locomotor sensitization did not relate to effects of PPA upon measures of undrugged locomotor activity. As illustrated in Figure 2b, PPA pretreatment produced no observable effect upon the locomotor behavior of saline-paired mice (one-way ANO$\mathrm{VA}, \mathrm{F}(3,36)=0.76, p=0.52)$. Moreover, PPA administration did not alter the locomotor response to being placed into the novel place-conditioning apparatus (Figure $3 \mathrm{~b}$ ) $(\mathrm{F}(3,68)=0.53, p=0.66)$, nor did it alter the locomotor response to the first saline injection (Figure 3c) $(\mathrm{F}(3,68)=0.33, p=0.80)$.

\section{Protracted Effects of Pre-Adolescent PPA upon Cocaine-Induced Stereotypy}

The reduction in the expression of cocaine-induced locomotor sensitization exhibited by PPA-pretreated mice did not relate to an increase in the expression of cocaineinduced stereotypy (Figure 4). As depicted in Figure 4a, a challenge injection of $15 \mathrm{mg} / \mathrm{kg}$ cocaine elicited the expression of locomotor sensitization in control mice treated thrice prior with cocaine in the home cage (SAL-COC), compared to mice injected acutely with cocaine (SAL-SAL), indicating sensitization. However, PPA pretreated mice injected thrice with $15 \mathrm{mg} / \mathrm{kg}$ cocaine in the home cage and then tested for cocaine-induced locomotion in the activity monitors (PPA-COC) did not differ from either group injected acutely with cocaine (Figure $4 \mathrm{a}$ ) (PPA pretreatment effect: $\mathrm{F}(1,28)=46.9, p<0.0001$; cocaine effect: $\mathrm{F}(1,28)=56.9, \quad p<0.0001 ; \quad$ PPA pretreatment $\times$ cocaine $\mathrm{F}(1,28)=31.9, p<0.0001)$. An examination of the stereotypy data indicated that whereas repeated cocaine administration induced a sensitization of stereotyped behaviors (Figure 4b), the expression of stereotypy was not affected by prior PPA experience (PPA pretreatment effect: $p=0.08$; cocaine effect: $F(1,28)=121.53, p<0.0001$; PPA pretreatment $\times$ cocaine: $p=0.193)$.

\section{Pre-Adolescent PPA Pretreatment Abolishes the Catecholamine Response to Cocaine in Adulthood}

Cocaine is a monoamine reuptake inhibitor (Koe, 1976) and both the psychomotor-activating and rewarding properties of this stimulant are putatively mediated by an enhance-
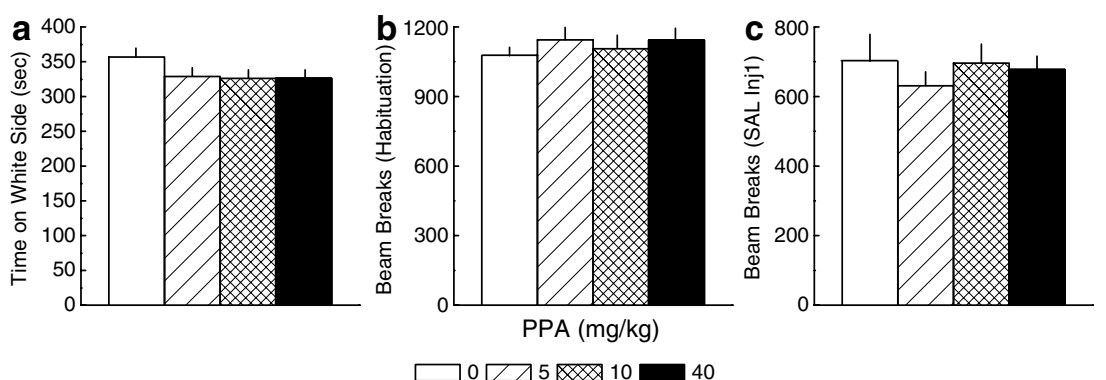

Figure 3 Pre-adolescent PPA exposure does not alter anxiety or spontaneous activity in adulthood. When assessed at 10 weeks of age, there was no observable effect of pre-adolescent treatment with PPA $(0-40 \mathrm{mg} / \mathrm{kg}$ ) regarding (a) the amount of time mice spent in the white compartment of the placeconditioning apparatus, (b) the locomotor activity exhibited by the animals in response to being placed in the place-conditioning apparatus for the first time or (c) the locomotor activity exhibited by the mice in response to their first saline (SAL) injection. The data represent the mean \pm SEM of I4-I8 animals. 


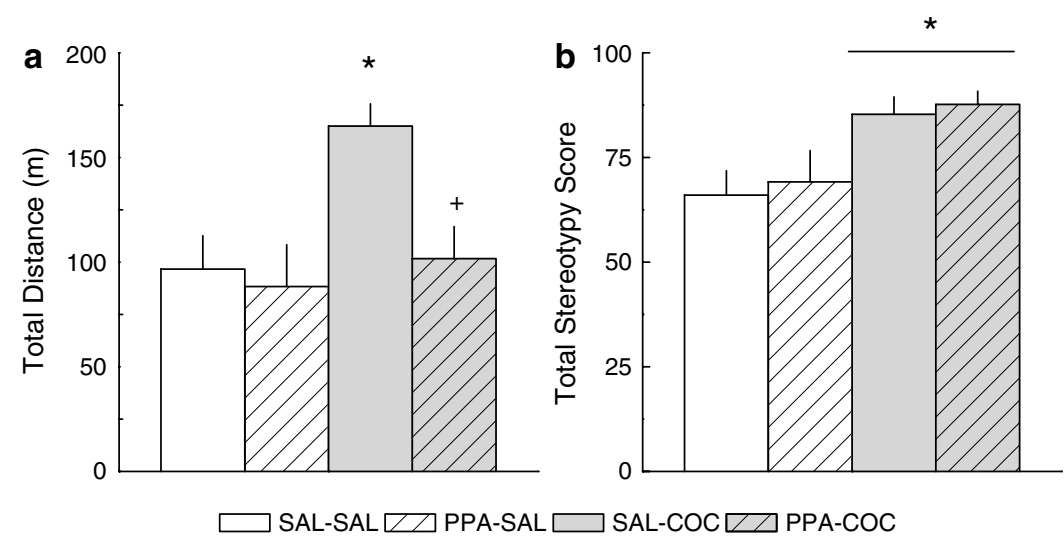

Figure 4 Differential effects of pre-adolescent PPA upon cocaine-induced locomotion and stereotypy. (a) Pre-adolescent PPA (0 or $40 \mathrm{mg} / \mathrm{kg}$; i.p.) administered during PNDs 2I-30 blocked the expression of locomotor sensitization when assessed in an unpaired testing environment. (b) Pre-adolescent PPA failed to alter the expression of stereotypy in either acute cocaine-treated or repeated cocaine-treated mice. The data represent the mean \pm SEM of $7-8$ animals. * $p<0.05$ vs repeated saline-treated mice (sensitization); $+p<0.05$ vs $0 \mathrm{mg} / \mathrm{kg}$ PPA.

ment in monoamine neurotransmission within the NAC (eg, Vanderschuren and Kalivas, 2000; Di Chiara et al, 2004; Hall et al, 2004). Thus, in vivo microdialysis was conducted in the NAC to relate the protracted behavioral effects of pre-adolescent PPA administration to alterations in the dopamine, norepinephrine and serotonin responses to acute and repeated cocaine. As summarized in Table 2, preadolescent PPA administration $(40 \mathrm{mg} / \mathrm{kg}$ during PNDs $21-$ 30) did not affect the average basal extracellular levels of any of the monoamines in the NAC (no main effects of, or interactions with, the PPA pretreatment factor: $p>0.05$ ). Despite this, a marked effect of pre-adolescent PPA administration was observed for the capacity of $15 \mathrm{mg} / \mathrm{kg}$ cocaine to elevate NAC extracellular levels of catecholamines (Figure 5). Whereas an acute injection of $15 \mathrm{mg} / \mathrm{kg}$ cocaine to control mice elevated extracellular levels of all three monoamines, the subchronic cocaine injection regimen induced a modest sensitization of this effect for dopamine (Figure $5 \mathrm{a}$ ) and norepinephrine (Figure $5 \mathrm{~b}$ ), but not for serotonin (Figure $5 \mathrm{c}$ ) (for dopamine, time effect: $\mathrm{F}(11,220)=9.94, p<0.0001$; cocaine injection number $\times$ time: $\mathrm{F}(11,220)=1.63, p=0.05$; for norepinephrine, time effect: $F(11,220)=5.85, \quad p<0.0001 ; \quad$ cocaine injection number $\times$ time: $\mathrm{F}(11,220)=2.51, p=0.005$; for serotonin, time effect: $\mathrm{F}(11,220)=4.23, p<0.0001$; cocaine injection number $\times$ time: $\mathrm{F}(11,220)=2.08, p=0.02)$. As illustrated in Figure $5 c$, pre-adolescent PPA administration did not alter the modest cocaine-induced rise in extracellular levels of serotonin (PPA pretreatment effect: $p=0.78$; PPA pretreatment $\times$ time: $p=0.48$; PPA $\times$ cocaine injection number $\times$ time: $p=0.69)$. However, $15 \mathrm{mg} / \mathrm{kg}$ cocaine failed to elicit a rise in extracellular dopamine (Figure 5a) and norepinephrine (Figure 5b) in the NAC of PPA-pretreated animals during either microdialysis session (for dopamine, PPA pretreatment effect: $\mathrm{F}(1,20)=11.52, p=0.003$; PPA pretreatment $\times$ time: $\mathrm{F}(11,220)=5.89, p<0.0001$; PPA pretreatment $\times$ cocaine injection number $\times$ time: $p=0.26$; for norepinephrine, PPA pretreatment effect: $\mathrm{F}(1,20)=12.77$, $p=0.002$; $\quad$ PPA pretreatment $\times$ time: $\quad \mathrm{F}(11,220)=3.25$, $p<0.0001$; PPA pretreatment $\times$ cocaine injection number $\times$ time: $\mathrm{F}(11,220)=2.84, p=0.002)$.
Table 2 Summary of the Basal Extracellular Levels of Monoamines and Amino Acids in the NAC of Saline- and PPA-Pretreated Mice before Injections I and 4 of $15 \mathrm{mg} / \mathrm{kg}$ Cocaine as Derived Using Conventional In Vivo Microdialysis

\begin{tabular}{|c|c|c|c|c|}
\hline \multirow{2}{*}{$\begin{array}{l}\text { Neurotransmitter } \\
\text { content }\end{array}$} & \multicolumn{2}{|c|}{ SAL-pretreated } & \multicolumn{2}{|c|}{$\begin{array}{c}40 \mathrm{mg} / \mathrm{kg} \\
\text { PPA-pretreated }\end{array}$} \\
\hline & Inj I & Inj4 & Inj I & Inj4 \\
\hline Dopamine (pg/sample) & $12.9 \pm 2.5$ & $12.8 \pm 1.3$ & $15.1 \pm 2.3$ & $13.7 \pm 1.7$ \\
\hline Norepinephrine (pg/sample) & $17.2 \pm 6.7$ & $13.7 \pm 1.2$ & $12.2 \pm 6.3$ & $13.5 \pm 3.2$ \\
\hline Serotonin (pg/sample) & $20.3 \pm 5.3$ & $19.4 \pm 1.7$ & $24.3 \pm 3.6$ & $23.7 \pm 3.2$ \\
\hline Glutamate (ng/sample) & $25.3 \pm 8.5$ & $22.4 \pm 3.8$ & $25.0 \pm 4.8$ & $20.6 \pm 2.9$ \\
\hline GABA (ng/sample) & $2.2 \pm 0.7$ & $1.8 \pm 0.2$ & $1.6 \pm 0.5$ & $1.0 \pm 0.1$ \\
\hline
\end{tabular}

Data represent the mean of three 20 -min samples \pm SEM of six to seven mice.

\section{Pre-Adolescent PPA Pretreatment Facilitates Cocaine-Induced Adaptations in Amino-Acid Neurotransmission}

A drug-induced imbalance in excitatory and inhibitory neurotransmission within the mesocorticolimbic circuit is a neural pathology implicated in the development of addiction-related behaviors (eg, Kalivas et al, 2005). Thus, we also examined for protracted effects of pre-adolescent PPA administration upon the glutamate and GABA responses to cocaine in the NAC (Figure 6). As summarized in Table 2, pre-adolescent PPA administration $(40 \mathrm{mg} / \mathrm{kg}$ during PNDs 21-30) did not affect the average basal extracellular levels of either glutamate or GABA in the NAC (no main effects of, or interactions with, the PPA pretreatment factor: $p>0.05$ ). Consistent with previous studies in rodents (eg, Pierce et al, 1996; Szumlinski et al, 2004a, b, 2005b, 2006), an acute injection of $15 \mathrm{mg} / \mathrm{kg}$ cocaine to either group of mice did not affect NAC extracellular levels of glutamate (Figure 6a); however, following repeated cocaine administration, cocaine elicited a significant increase in glutamate above baseline in control mice (time effect: $\mathrm{F}(11,253)=1.79$, 

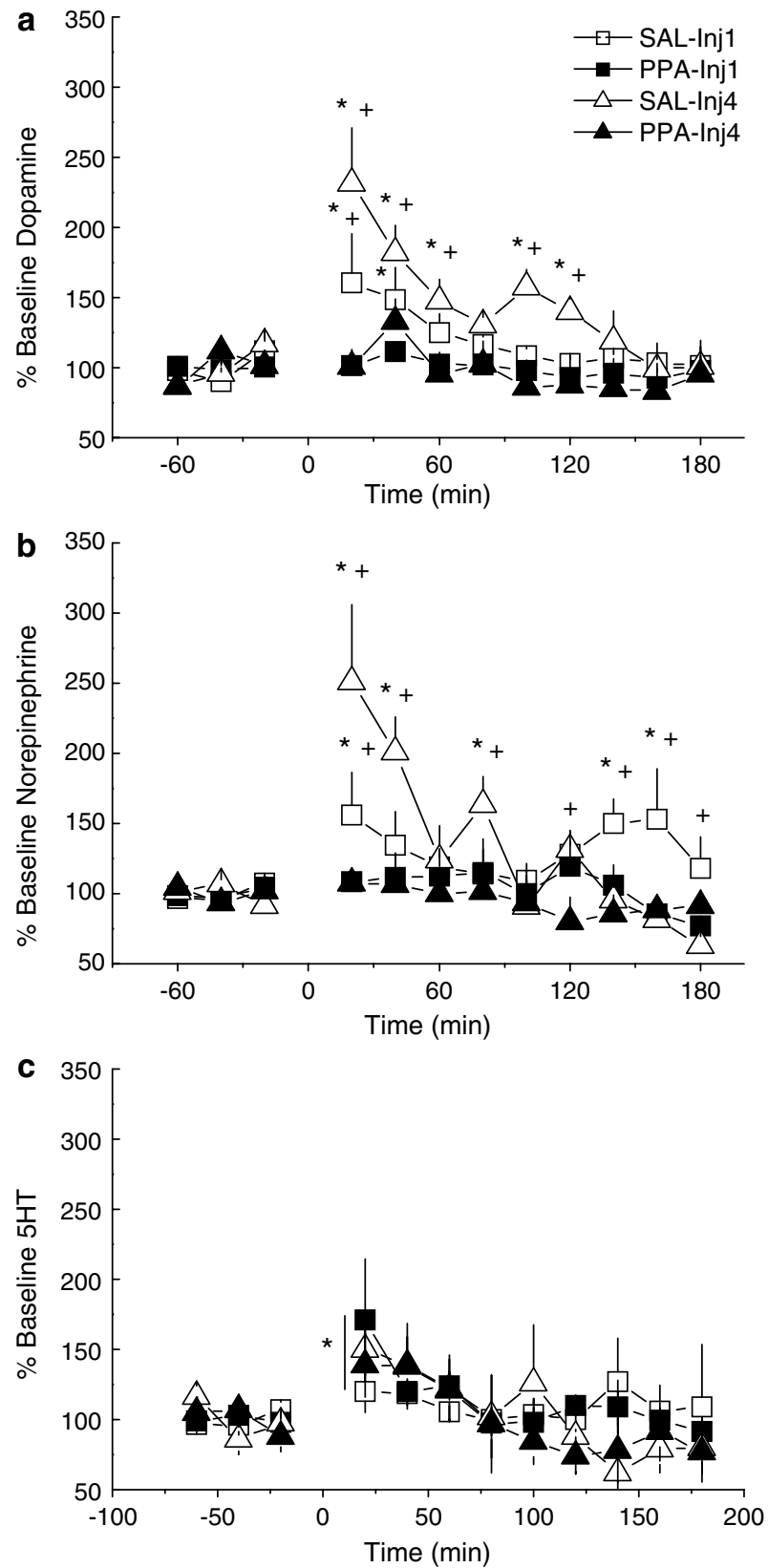

Figure 5 Enduring changes in the NAC catecholamine response to cocaine produced by pre-adolescent PPA. An acute injection of $15 \mathrm{mg} / \mathrm{kg}$ cocaine causes a sensitized rise in extracellular levels of catecholamines in saline (SAL)-pretreated animals, whereas pre-adolescent PPA administration (40 mg/ $/ \mathrm{kg}$ ) during PNDs 2I-30 prevented the increase in extracellular dopamine (a) and norepinephrine (b) produced by cocaine (one or four injections of $15 \mathrm{mg} / \mathrm{kg}$ ). (c) In contrast, PPA pre-exposure did not affect the capacity of $15 \mathrm{mg} / \mathrm{kg}$ to elevate NAC levels of serotonin. Data represent the mean percent change from baseline \pm SEM of 6-8 animals. $* p<0.05$ vs Inj I (sensitization); $+p<0.05$ vs SAL (0 mg/kg PPA).

$p=0.06$; time $\times$ cocaine injection number: $\mathrm{F}(11,253)=3.20$, $p<0.0001)$. As depicted in Figure $6 \mathrm{a}$, the cocaine-sensitized increase in extracellular glutamate was significantly greater in mice pretreated with PPA (PPA pretreatment effect: $p=0.70$; PPA $\times$ time: $p=0.60$; PPA pretreatment $\times$ cocaine injection number $\times$ time: $\mathrm{F}(11,253)=1.84, p=0.04)$. As illustrated in Figure $6 \mathrm{~b}$, control animals did not exhibit a
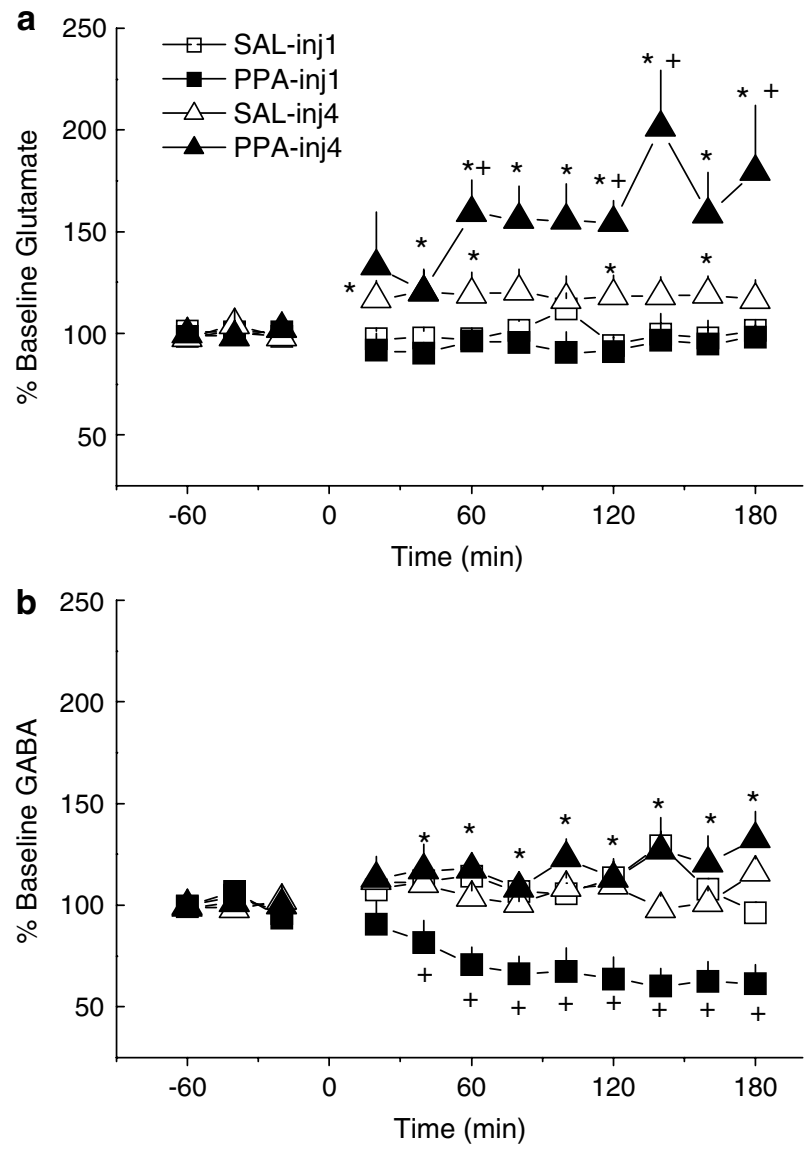

Figure 6 Enduring changes in the NAC amino acid response to cocaine produced by pre-adolescent PPA. (a) Whereas pre-adolescent PPA administration $(40 \mathrm{mg} / \mathrm{kg}$ ) during PNDs $21-30$ did not alter the acute glutamate response to $15 \mathrm{mg} / \mathrm{kg}$ cocaine, it facilitated the development of cocaine-induced glutamate sensitization produced by four injections of $15 \mathrm{mg} / \mathrm{kg}$ cocaine. (b) Neither acute nor repeated cocaine altered extracellular GABA in saline (SAL)-pretreated mice. Acute cocaine lowered extracellular GABA below baseline in PPA-pretreated mice and this effect showed tolerance with repeated cocaine administration. Data represent the mean percent change from baseline + SEM of 6-8 animals. ${ }^{*} p<0.05$ vs Inj I (sensitization); $+p<0.05$ vs SAL (0 mg/kg PPA).

change in extracellular GABA following either acute or repeated cocaine (time effect: $p=0.78$; cocaine injection number $\times$ time: $\quad \mathrm{F}(11,253)=2.77, \quad p=0.002) ; \quad$ however, PPA pretreated mice exhibited a large reduction in extracellular levels of GABA following the acute cocaine injection and this effect showed tolerance with repeated cocaine administration (PPA pretreatment effect: 0.29; PPA pretreatment $\times$ time: $\mathrm{F}(11,253)=2.41, p=0.007$; PPA pretreatment $\times$ cocaine injection number $\times$ time: $F(11,253)=$ $4.00, p<0.0001)$.

\section{DISCUSSION}

For nearly 50 years, PPA was an active ingredient commonly found in popular children's OTC cough, cold, and allergy medicines. As PPA is a sympathomimetic (Hoffman, 2001), which can substitute for illicit stimulant drugs in self-administration and drug discrimination 
studies (Woolverton et al, 1986; Chait et al, 1988; Lee et al, 1989; Wellman et al, 1989), the present study sought to determine whether exposure to PPA during the juvenile period of development produced protracted effects upon the behavioral and neurochemical effects of cocaine in adulthood. Here, we show that PPA exposure during the pre-adolescent period (PND 21-30) dose-dependently enhanced cocaine-conditioned reward and reduced cocaineinduced locomotor sensitization in mice (Figures 2 and 4). The protracted behavioral effects of pre-adolescent PPA exposure were accompanied by an altered dopamine, norepinephrine, glutamate, and GABA response to cocaine when assessed in adulthood. Pre-adolescent PPA exposure abolished the catecholamine response to cocaine in the NAC (Figure 5), facilitated the development of cocaine-induced glutamate sensitization (Figure 6a) and altered the GABA response to cocaine (Figure 6b). Despite these observed behavioral and neurochemical interactions between PPA and cocaine, pre-adolescent PPA produced no observable effects upon body weight during pre-adolescence (Figure 1) nor did it affect measures of basal anxiety, spontaneous locomotion or cocaine-induced stereotypy in adulthood (Figures 2-4). These data provide the first evidence that repeated exposure to PPA during pre-adolescence induces enduring neuroadaptations in NAC neurotransmission that may increase vulnerability to cocaine reward in adulthood.

\section{PPA Effects during Pre-Adolescence}

The systemic administration of PPA $(40 \mathrm{mg} / \mathrm{kg})$ produced a rapid elevation in plasma levels of PPA and the half-life of the drug in the plasma of juvenile mice following i.p. injection was estimated to be approximately $1.5-2 \mathrm{~h}$ (Figure 1a). Although sympathomimetic drugs can exert psychomotor-activating effects (eg, Eisenberg et al, 1987; Miller et al, 1999; Mittleman et al, 1993), earlier reports for PPA conducted in adult rats failed to observe hyperactivity in response to systemic injections of PPA (Eisenberg et al, 1987; Mittleman et al, 1993). As spontaneous locomotion, as well as drug-induced changes in motor hyperactivity, can depend upon the age of animal (eg, Bolanos et al, 1998; Carlezon and Konradi, 2004; Dafny and Yang, 2006; Niculescu et al, 2005; Spear and Brake, 1983), we examined for changes in the locomotor activity of juvenile mice in response to repeated PPA administration. Consistent with earlier reports for the locomotor effects of PPA in adult rats (Eisenberg et al, 1987; Mittleman et al, 1993), PPA administration to juvenile mice did not elicit motor hyperactivity, but rather suppressed locomotion in a doseindependent manner, relative to saline controls (Figure $1 \mathrm{~b}$ ). The earlier report by Mittleman et al (1993) implicated the locomotor-suppressive effects of even low doses of PPA (ie, $5 \mathrm{mg} / \mathrm{kg}$ ) in the anorectic properties of this drug. However, we failed to detect any significant effect of PPA administration on body weight gain during PPA administration (Figure 1c and d) and the body weight of adult mice during the cocaine studies did not vary as a function of prior PPA treatment (data not shown).

In PPA-treated juvenile mice, we observed an increase in the expression of locomotor activity across PPA injections, indicative of sensitization. However, a similar increase in locomotor activity was observed also in control mice injected repeatedly with saline (Figure $1 \mathrm{~b}$ ). In our hands, the repeated administration of saline to adult mice typically induces either no change, but more often, a reduction in locomotion across injections, indicative of habituation to the environment, handling, and injection procedures (see Figure 2b; Szumlinski et al, 2002, 2004a, 2005a-c). Whether the change in locomotor behavior of saline controls reflected an age-dependent general increase in locomotor hyperactivity (eg, Niculescu et al, 2005; Spear and Brake, 1983) or a sensitized response to the injection stressor cannot be discerned by the results of the present study. However, in support of the latter possibility, the locomotor response to an acute saline injection does not differ between mice aged 21 and 28 days (Guerriero et al, 2006). Nonetheless, our data clearly demonstrate that PPA administration suppresses, rather than enhances, locomotor activity in juvenile mice. Thus, although PPA shares discriminative stimulus properties with illicit stimulant drugs (eg, Lee et al, 1989), it does not possess motoractivating properties in either adult or juvenile mice (eg, Eisenberg et al, 1987; Mittleman et al, 1993; present study).

\section{Juvenile Licit Drug Exposure and Stimulant Addiction-Related Behaviors in Adulthood}

The marked rise in the prescription of psychotropic drugs to children (Zito et al, 2000) has raised significant concern over the long-term psychobiological effects of prescription drug exposure during periods of brain development (cf., Carlezon and Konradi, 2004). In addition to its prevalence as the active ingredient in children's cough, cold, and allergy medications, PPA is also a major metabolite of methylphenidate (eg, Patrick et al, 1981) - the most highly prescribed medicine for the treatment of Attention-Deficit/ Hyperactivity Disorder in children (eg, Zito et al, 2000). The present data for PPA are consistent with the notion that exposure to licit psychotropic drugs during periods of brain development produces enduring biobehavioral adaptations that persist into adulthood and extend these earlier findings for the prescription drug methylphenidate (cf., Carlezon and Konradi, 2004) to a formerly common OTC sympathomimetic. However, in contrast to earlier reports for methylphenidate (Andersen et al, 2002; Biederman et al, 1999; Carlezon et al, 2003; Mague et al, 2005; TorresReveron and Dow-Edwards, 2005), juvenile exposure to PPA enhanced the capacity of cocaine to elicit place conditioning in adulthood, but blocked the expression of cocaineinduced locomotor sensitization in both cocaine-paired and -unpaired environments (Figures 2 and 4).

The precise psychological underpinnings mediating the effects of juvenile PPA exposure upon cocaine-conditioned reward are unclear. A full dose-response characterization of the interactions between juvenile PPA administration and cocaine is required. However the observation that PPA pretreatment enhanced cocaine-conditioned reward, but prevented the development of cocaine-induced locomotor sensitization without influencing the expression of cocaineinduced stereotypy, suggests that juvenile PPA exposure produced some general increase in behavioral sensitivity to cocaine. Cocaine is anxiogenic in both humans and laboratory animals and withdrawal from repeated cocaine 
administration induces a negative affective state (eg, Cohen, 1972; Covington and Miczek, 2003; Deroche-Gamonet et al, 2004; Gawin and Kleber, 1986; Gawin, 1991; Gillman et al, 2006; Jung et al, 2002; Markou and Koob, 1991; McGregor et al, 2005; Paine et al, 2002). Moreover, the aversive properties of cocaine can become conditioned to the environment in which the drug is repeatedly administered (eg, Ettenberg and Geist, 1991; Raven et al, 2000). Indeed, studies of both humans and laboratory animals have implicated an enhancement of cocaine-induced psychomotor activation (notably stereotypies) and aversion or an increase in anhedonia as mechanisms to account for the observed 'protective' effect against subsequent cocaine addiction-related behaviors in adulthood engendered by juvenile exposure to methylphenidate (Andersen et al, 2002; Biederman et al, 1999; Carlezon et al, 2003; Mague et al, 2005; Torres-Reveron and Dow-Edwards, 2005). Yet, our interactions between juvenile PPA treatment and cocaine administration in adulthood are distinct, if not opposite, to those observed previously for methylphenidate (eg, Andersen et al, 2002; Augustyniak et al, 2006; Carlezon et al, 2003; Torres-Reveron and Dow-Edwards, 2005). Thus, perhaps a converse mechanism may be invoked to account for our data; pre-adolescent PPA administration may facilitate the development of cocaine-conditioned reward by reducing either the unconditioned or the conditioned aversive effects of cocaine. Although this mechanism is under intense investigation by our laboratory, our present observation that juvenile PPA treatment prevented the development of cocaine-induced locomotor sensitization, a classic animal model of psychosis (eg, Scheel-Kruger et al, 1977; Kuczenski et al, 1991; Post and Kopanda, 1976; Segal and Kuczenski, 1997), is consistent with this hypothesis.

In addition to positive and negative rewarding properties, psychomotor-stimulant drugs have behavioral disinhibitory properties (Olausson et al, 2000; Spinella, 2003; Szumlinski et al, 2000a). Thus, it may be postulated that juvenile PPA exposure increased the time spent on originally nonpreferred, cocaine-paired, side by facilitating behavioral disinhibition. However, two observations argue against a major role for changes in behavioral disinhibition in the observed facilitation of cocaine-induced place conditioning by juvenile PPA exposure. First, when assessed for compartment preference at the outset of place conditioning, the large majority of animals avoided the white compartment of the apparatus and significant pretreatment differences were not observed in this regard (Figure 3a). Moreover, PPA pretreatment reduced locomotor activity during pre-adolescence (Figure 1), whereas it failed to produce a protracted effect upon the expression of locomotor activity elicited by either placement into a novel environment (Pre-Test1) or in response to a saline injection (Figure 3). Juvenile PPA treatment produced no observable protracted effects upon these measures of anxiety/behavioral disinhibition. Also, the facilitation of time spent in the originally non-preferred compartment by PPA-pretreated mice was observed in the absence of cocaine and thus, cannot be attributed to a change in the behavioral disinhibitory properties of cocaine per se. As a biased place-conditioning procedure was employed in the present study, we cannot negate a role for other nonreward mechanisms to account for the increase in the time spent in the cocaine-paired environment exhibited by PPApretreated mice. However, for the reasons presented above, we argue that an attenuation of the psychomotor-sensitizing properties of cocaine is a plausible explanation to account for the apparent 'pro-addictive' effects of juvenile PPA exposure.

\section{Pre-Adolescent PPA Produces Persistent Perturbations in NAC Extracellular Catecholamine Levels}

Cocaine, methylphenidate, and PPA all block the reuptake of norepinephrine (Hoffman, 2001; Koe, 1976; Solanto, 1998); however, PPA differs from both cocaine and methylphenidate in that it does not prevent dopamine reuptake, but acts as a direct, nonselective adrenergic receptor agonist (Hoffman, 2001). Thus, we reasoned that the protracted effects of PPA vis-à-vis cocaine-induced changes in behavior in adulthood might reflect selective perturbations in noradrenergic transmission that, in turn, may alter the activity of brain regions involved in drug reward and locomotor hyperactivity, such as the NAC. Few studies have examined the neurochemical effects of PPA administration in laboratory animals. PPA produces only a modest effect upon dopamine release in striatal synaptosomal preparations, it enhances both dopamine and norepinephrine release in cortical preparations (Baldessarini and Harris, 1974). An examination of the effects of repeated PPA administration upon tissue content of dopamine revealed a selective reduction in tissue content of dopamine in the prefrontal cortex, but not in the NAC of rhesus monkeys (Woolverton et al, 1986). Consistent with this latter observation, we failed to detect any observable protracted effect of pre-adolescent PPA exposure $(10 \times 40 \mathrm{mg} / \mathrm{kg})$ upon basal extracellular levels of monoamines in the NAC. However, we observed a complete blockade of the capacity of both acute and repeated cocaine to elevate extracellular levels of dopamine and norepinephrine in the NAC of adult mice (Figure 5a and b). Interestingly, this protracted PPA effect did not generalize to all monoamines, as the serotonin response to cocaine was unaffected (Figure $5 \mathrm{c}$ ). As cocaine is a monoamine reuptake inhibitor, the capacity of cocaine to elevate extracellular levels of monoamines in terminal regions depends upon its binding to cell-surface monoamine transporter proteins and upon the release of these neurotransmitters into the synaptic cleft (Koe, 1976). In the NAC, norepinephrine and dopamine release is inhibited by $\alpha 2$ adrenergic receptors localized on norepinephrine and dopamine terminals (Ihalainen and Tanila, 2004). Thus, we postulate two potential mechanisms to account for our observed catecholamine effects of juvenile PPA exposure. First, pre-adolescent PPA may produce a persistent perturbation in NAC catecholamine release via a sensitization of $\alpha 2$ adrenergic receptor function. Second, preadolescent PPA may upregulate the expression or function of the dopamine and norepinephrine transporters, necessitating the administration of higher doses of cocaine to elicit a rise in extracellular levels of these neurotransmitters. Studies have commenced in the laboratory to investigate these possibilities and preliminary data support a potential role for both mechanisms in mediating the blunted catecholamine response to cocaine produced by pre- 
adolescent PPA exposure (Szumlinski, Ary, Renton, and Tieu, unpublished data).

The behavioral relevance of the blunted NAC catecholamine response to cocaine in PPA-pretreated mice is not clear at the present time. Dopamine, and to a lesser extent norepinephrine, have been implicated in mediating drug reward, and in particular, drug reward-related learning (eg, Di Chiara, 1999; Everitt et al, 1999; Robinson and Berridge, 2001). However, the PPA-induced facilitation of cocaineconditioned reward in adulthood was associated with a reduction in, not an enhancement of, the catecholamine response to cocaine. Both norepinephrine and dopamine are implicated also in the psychomotor-activating/psychogenic effects of stimulant drugs (Sherer, 1988). Yet, despite profound effects of juvenile PPA treatment upon the catecholamine response to acute cocaine (Figure 5), we failed to observe group differences in the acute locomotor or stereotypic response to cocaine in adulthood (Figure 4). The only observed effect of pre-adolescent PPA administration that is consistent with a blunted catecholamine system is the attenuation of locomotor sensitization. However, two major lines of evidence argue against a direct relationship between the protracted effects of juvenile PPA exposure and the locomotor- and catecholamine-sensitizing effects of cocaine. For one, the locomotor-activating or -sensitizing effects of psychomotor stimulants can be dissociated from the ability of this drug class to elevate extracellular levels of dopamine and norepinephrine in the NAC (eg, Frantz et al, 2006; Ito et al, 2006; Szumlinski et al, 2000a, b, 2004b, 2005b; Zhang et al, 2006). These observations are supported by the present finding that despite reducing the capacity of acute cocaine to elevate NAC levels of dopamine and norepinephrine, PPA pretreatment did not alter the acute motor-stimulatory effects of cocaine. Second, considerable behavioral pharmacological evidence demonstrates that dopamine or norepinephrine receptor activation is not necessary for the development of cocaine-induced behavioral sensitization (eg, Szumlinski et al, 2004b; Thiébot et al, 1981; Vanderschuren et al, 2003; see also review by Vanderschuren and Kalivas, 2000). Thus, it is not likely that a causal relationship exists between the deficit in catecholamine responsiveness to cocaine and the lack of behavioral sensitization observed in PPA pretreated mice in the present study.

\section{Pre-Adolescent PPA Facilitates Cocaine-Induced Plasticity in NAC Glutamate Transmission}

Cocaine-induced sensitization of glutamate release within the NAC is a putative neural substrate for both the addictive and motor-sensitizing properties of cocaine (Pierce et al, 1996; Baker et al, 2003; Szumlinski et al, 2004a, b, 2006). Consistent with current glutamate theories of addiction (eg, Everitt and Wolf, 2002; Kalivas et al, 2005), the enhancement in cocaine-conditioned reward observed in PPApretreated mice was paralleled by significantly greater cocaine-induced glutamate sensitization in the NAC. Moreover, in control mice, the presence of cocaine-induced motor sensitization was accompanied by a sensitized NAC glutamate response to cocaine. However, the expression of sensitized locomotor behavior by PPA mice was inversely related to the extent to which repeated cocaine elicited glutamate sensitization in the NAC. Given that only one dose of cocaine was investigated in the present study, one might argue that cocaine may have induced the expression of focused, stereotyped behaviors in PPA-pretreated mice and index of increased sensitivity to cocaine. However, we failed to detect group differences in cocaine-induced stereotypy elicited by $15 \mathrm{mg} / \mathrm{kg}$ cocaine in either acute or repeated cocaine-treated mice (Figure 4). A second possibility to account for the apparent discrepancy between cocaine-induced locomotor and glutamate sensitization is that whereas glutamate sensitization in the NAC may be necessary for the development of cocaine-induced motor sensitization (Pierce et al, 1996), it is not sufficient to induce this behavioral change. As cocaine failed to elicit a rise in NAC extracellular levels of catecholamines in PPApretreated mice, it is plausible that adaptations in catecholamine and glutamate transmission must co-occur for the full expression of this form of cocaine-induced behavioral plasticity. Whereas the results of the present study cannot discern between these two possibilities, the present results nonetheless indicate that pre-adolescent PPA administration produces an enduring effect upon the cocaine responsiveness of glutamate terminals in the NAC. Whereas the precise mechanisms mediating the protracted effects of PPA administration upon cocaine-induced glutamate release in the NAC remain to be determined, adrenoreceptors regulate glutamate release within the prefrontal cortex (Golembiowska and Zylewska, 1999; Marek and Aghajanian, 1999). As our current working hypothesis is that the repeated stimulation of adrenoreceptors by PPA during pre-adolescence induces alterations in receptor function that endure into adulthood, future studies in our laboratory will be examining more closely also the role for these two adrenoreceptors in regulating cocaineinduced changes in glutamate transmission within the NAC as it pertains to the protracted effects of pre-adolescent PPA administration.

\section{Pre-Adolescent PPA Alters the GABA Response to Cocaine}

The majority of GABA released within the NAC is derived from neuronal sources (Xi et al, 2003), which include the small population of aspiny GABAergic interneurons, the extensive network of recurrent collaterals of medium spiny neurons and GABAergic afferents to the NAC (including the ventral pallidum, ventral tegmental area or olfactory nucleus) (Smith and Bolam, 1990; Brog et al, 1993; Pennartz et al, 1994). Withdrawal from repeated cocaine administration increases basal GABA content in the NAC and this neuroadaptation has been proposed to contribute to the dysregulation of NAC physiology following repeated cocaine experience (Xi et al, 2003). Despite now a decade of research concerned with the role for cocaine-induced alterations in NAC glutamate transmission in mediating the behavioral consequences of repeated stimulant administration (Everitt and Wolf, 2002; Kalivas et al, 2005), the effects of a cocaine injection upon extracellular GABA levels within the NAC are currently undescribed. In the present study, pre-adolescent PPA administration facilitated an inhibition of extracellular GABA following an acute cocaine injection. Moreover, the cocaine-induced reduction in extracellular 
GABA observed in PPA-pretreated mice showed tolerance with repeated cocaine administration, with the fourth injection of cocaine elevating NAC extracellular GABA levels above baseline (ie, sensitization) (Figure 6b). A considerable amount of behavioral pharmacological data strongly implicate GABAergic neurotransmission in mediating the rewarding and psychomotor-activating effects of cocaine (eg, Brebner et al, 2002; Gardner et al, 2002; Itzhak and Martin, 2000; Roberts, 2005; Steketee and Beyer, 2005). However, despite the large difference in their GABA response to an acute cocaine injection, PPA-pretreated mice did not differ from controls in terms of their locomotor response to an acute injection of this drug. Furthermore, the subchronic cocaine regimen employed in the present study induced both locomotor sensitization and conditioned reward in control mice, yet did not alter levels of GABA in the NAC either basally or following a cocaine injection. Thus, whereas a history of cocaine experience may elevate NAC GABA content (Xi et al, 2003) and enhance GABA release in the ventral pallidum in a manner that correlates with sensitized lever pressing behavior (Tang et al, 2005), the precise relationship between our GABAergic findings in PPA-pretreated mice and behavioral and neurochemical responsiveness to cocaine remain unresolved.

\section{CONCLUSIONS}

Until December 2005, PPA was a common active ingredient found in popular children's cold, cough and allergy medicines. This work demonstrates for the first time that repeated administration of PPA to juvenile mice produces a protracted increase in cocaine reward, concomitant with a reduction in cocaine-induced locomotor sensitization. The enduring behavioral effects of early PPA exposure are associated with deficits in catecholaminergic transmission, as well as a facilitation of cocaine-induced sensitization of amino-acid transmission within the NAC. As PPA was available for 50 years in both prescription and OTC preparations and is a major metabolite of methylphenidate, a more intensive investigation into the protracted psychobiological consequences effects of early exposure to PPA, as well as to related and available OTC sympathomimetics (eg, pseudoephedrine), is warranted to gain a more solid understanding of the mechanism(s) through which childhood exposure to sympathomimetics may impact vulnerability to addictive and psychotic disorders in later life.

\section{ACKNOWLEDGEMENTS}

This work was supported by funds provided through the University of California at Santa Barbara and a NARSAD Young Investigator's Award to KKS.

\section{REFERENCES}

Adriani W, Granstrem O, Macri S, Izykenova G, Dambinova S, Laviola G (2004). Behavioral and neurochemical vulnerability during adolescence in mice: studies with nicotine. Neuropsychopharmacology 29: 869-878.
Andersen SL, Arvanitogiannis A, Pliakas AM, LeBlanc C, Carlezon Jr WA (2002). Altered responsiveness to cocaine in rats exposed to methylphenidate during development. Nat Neurosci 5: 13-14.

Augustyniak PN, Kourrich S, Rezazadeh SM, Stewart J, Arvanitogiannis A (2006). Differential behavioral and neurochemical effects of cocaine after early exposure to methylphenidate in an animal model of attention deficit hyperactivity disorder. Behav Brain Res 167: 379-382.

Badiani A, Oates MM, Robinson TE (2000). Modulation of morphine sensitization in the rat by contextual stimuli. Psychopharmacology 151: 273-282.

Badiani A, Robinson TE (2004). Drug-induced neurobehavioral plasticity: the role of environmental context. Behav Pharmacol 15: 327-339.

Baker DA, McFarland K, Lake RW, Shen H, Tang XC, Toda S et al (2003). Neuroadaptations in cystine-glutamate exchange underlie cocaine relapse. Nat Neurosci 6: 743-749.

Baldessarini RJ, Harris JE (1974). Effects of amphetamines on the metabolism of catecholamines in the rat brain. J Psychiatr Res 11: 41-43.

Bardo MT, Bevins BA (2000). Conditioned place preference: what does it add to our preclinical understanding of drug reward? Psychopharmacology 153: 31-43.

Belzung C, Misslin R, Vogel E, Dodd RH, Chapouthier G (1987). Anxiogenic effects of methyl- $\beta$-carboline-carboxylate in a light/ dark choice situation. Pharmacol Biochem Behav 28: 29-33.

Biederman J, Wilens T, Mick E, Spencer T, Faraone SV (1999). Pharmacotherapy of attention deficit/hyperactivity disorder reduces risk for substance abuse disorder. Pediatrics 104: e20, $1-5$.

Bolanos CA, Glatt SJ, Jackson D (1998). Subsensitivity to dopaminergic drugs in periadolescent rats: a behavioral and neurochemical analysis. Brain Res Dev Brain Res 111: 25-33.

Brebner K, Childress AR, Roberts DC (2002). A potential role for GABA(B) agonists in the treatment of psychostimulant addiction. Alcohol Alcohol 37: 478-484.

Brog JS, Salyapongse A, Deutch AY, Zahm DS (1993). The patterns of afferent innervation of the core and shell in the 'accumbens' part of the rat ventral striatum: immunohistochemical detection of retrogradely transported fluoro-gold. J Comp Neurol 338: 255-278.

Browman KE, Badiani A, Robinson TE (1998). The influence of environment on the induction of sensitization to the psychomotor activating effects of intravenous cocaine in rats is dosedependent. Psychopharmacology 137: 90-98.

Carlezon Jr WA, Konradi C (2004). Understanding the neurobiological consequences of early exposure to psychotropic drugs: linking behavior with molecules. Neuropharmacology 47(Suppl 1): 47-60.

Carlezon Jr WA, Mague SC, Andersen SL (2003). Enduring behavioral effects of early exposure to methylphenidate in rats. Biol Psychiat 54: 1330-1337.

Chait LD, Uhlenhuth EH, Johanson CE (1988). Phenylpropanolamine: reinforcing and subjective effects in normal human volunteers. Psychopharmacology 96: 212-217.

Cirulli F, Laviola G (2000). Paradoxical effects of D-amphetamine in infant and adolescent mice: role of gender and environmental risk factors. Neurosci Biobehav Rev 24: 73-84.

Cohen S (1972). Cocaine. J Amer Med Assoc 231: 74-75.

Covington III HE, Miczek KA (2003). Vocalizations during withdrawal from opiates and cocaine: possible expressions of affective distress. Eur J Pharmacol 467: 1-13.

Dafny N, Yang PB (2006). The role of age, genotype, sex, and route of acute and chronic administration of methylphenidate: a review of its locomotor effects. Brain Res Bull 68: 393-405.

Deroche-Gamonet V, Belin D, Piazza PV (2004). Evidence for addiction-like behavior in the rat. Science 305: 1014-1017. 
Di Chiara G (1999). Drug addiction as dopamine-dependent associative learning disorder. Eur J Pharmacol 375: 13-30.

Di Chiara G, Bassareo V, Fenu S, De Luca MA, Spina L, Cadoni C et al (2004). Dopamine and drug addiction: the nucleus accumbens shell connection. Neuropharmacology 47(Suppl 1): 227-241.

Eisenberg MS, Maher TJ, Silverman HI (1987). A comparison of the effects of phenylpropanolamine, d-amphetamine and dnorpseudoephedrine on open-field locomotion and food intake in the rat. Appetite 9: 31-37.

Ettenberg A, Geist TD (1991). Animal model for investigating the anxiogenic effects of self-administered cocaine. Psychopharmacology 103: 455-461.

Everitt BJ, Parkinson JA, Olmstead MC, Arroyo M, Robledo P, Robbins TW (1999). Associative processes in addiction and reward. The role of amygdala-ventral striatal subsystems. Ann NY Acad Sci 877: 412-438.

Everitt BJ, Wolf ME (2002). Psychomotor stimulant addiction: a neural systems perspective. J Neurosci 22: 3312-3320.

Frantz KJ, O’Dell LE, Parsons LH (2006). Behavioral and neurochemical responses to cocaine in periadolescent and adult rats. Neuropsychopharmacology [E-pub ahead of print; doi:10.1038/sj.npp.1301130].

Gardner EL, Schiffer WK, Horan BA, Highfield D, Dewey SL, Brodie JC et al (2002). Gamma-vinyl GABA, an irreversible inhibitor of GABA transaminase, alters the acquisition and expression of cocaine-induced sensitization in male rats. Synapse 46: 240-250.

Gawin FH (1991). Cocaine addiction: psychology and neurophysiology. Science 251: 1580-1586.

Gawin FH, Kleber HD (1986). Abstinence symptomatology and psychiatric diagnosis in cocaine abusers. Clinical observations. Arch Gen Psychiatry 43: 107-113.

Gillman MA, Lichtigfeld FJ, Harker N (2006). Psychotropic analgesic nitrous oxide for acute cocaine withdrawal in man. Int J Neurosci 116: 847-857.

Golembiowska K, Zylewska A (1999). Effect of antidepressant drugs on veratridine-evoked glutamate and aspartate release in rat prefrontal cortex. Pol J Pharmacol 51: 63-70.

Guerriero RM, Hayes MM, Dhaliwal SK, Ren JQ, Kosofsky BE (2006). Preadolescent methylphenidate versus cocaine treatment differ in the expression of cocaine-induced locomotor sensitization during adolescence and adulthood. Biol Psychiatry 60: 1171-1180.

Hall FS, Sora I, Drgonova J, Li XF, Goeb M, Uhl GR (2004). Molecular mechanisms underlying the rewarding effects of cocaine. Ann NY Acad Sci 1025: 47-56.

Hoffman BB (2001). Catecholamines, sympathomimetics, and adrenergic receptor antagonists. In: Hardman JG, Limbird LE, Gilman AG (eds). Goodman and Gilman's The Pharmacological Basis of Therapeutics. McGraw-Hill: New York. pp 215-268.

Ihalainen JA, Tanila $\mathrm{H}$ (2004). In vivo regulation of dopamine and noradrenaline release by alpha2A-adrenoceptors in the mouse nucleus accumbens. J Neurochem 91: 49-56.

Itzhak Y, Martin JL (2000). Effect of riluzole and gabapentin on cocaine- and methamphetamine-induced behavioral sensitization in mice. Psychopharmacology 151: 226-233.

Ito K, Abekawa T, Koyama T (2006). Relationship between development of cross-sensitization to MK-801 and delayed increases in glutamate levels in the nucleus accumbens induced by a high dose of methamphetamine. Psychopharmacology 187: 293-302.

Jung ME, Lal H, Gatch MB (2002). The discriminative stimulus effects of pentylenetetrazol as a model of anxiety: recent developments. Neurosci Biobehav Rev 26: 429-439.

Kalivas PW, Volkow N, Seamans J (2005). Unmanageable motivation in addiction: a pathology in prefrontal-accumbens glutamate transmission. Neuron 45: 647-650.
Koe BK (1976). Molecular geometry of inhibitors of the uptake of catecholamines and serotonin in synaptosomal preparations of rat brain. J Pharmacol Exp Ther 199: 649-661.

Kuczenski R, Segal DS, Aizenstein ML (1991). Amphetamine, cocaine, and fencamfamine: relationship between locomotor and stereotypy response profiles and caudate and accumbens dopamine dynamics. J Neurosci 11: 2703-2712.

Lee F, Stafford I, Hoebel BG (1989). Similarities between the stimulus properties of phenylpropanolamine and amphetamine. Psychopharmacology 97: 410-412.

Lominac KD, Kapasova Z, Hannun RA, Patterson C, Middaugh LD, Szumlinski KK (2006). Behavioral and neurochemical interactions between Group 1 mgluR antagonists and ethanol: potential insight into their anti-addictive properties. Drug Alcohol Dep 85: 142-156.

Lominac KD, Oleson EB, Pava M, Klugmann M, Schwarz MK, Seeburg PH et al (2005). Distinct roles for different Homer1 isoforms in behaviors and associated prefrontal cortex function. J Neurosci 25: 11586-11594.

Mague SD, Andersen SL, Carlezon Jr WA (2005). Early developmental exposure to methylphenidate reduces cocaine-induced potentiation of brain stimulation reward in rats. Biol Psychiatry 57: $120-125$.

Marek GJ, Aghajanian GK (1999). 5-HT2A receptor or alpha1adrenoceptor activation induces excitatory postsynaptic currents in layer V pyramidal cells of the medial prefrontal cortex. Eur J Pharmacol 367: 197-206.

Mariathasan EA, Stolerman IP (1992). Drug discrimination studies in rats with caffeine and phenylpropanolamine administered separately and as mixtures. Psychopharmacology 109: 99-106.

Markou A, Koob GF (1991). Postcocaine anhedonia. An animal model of cocaine withdrawal. Neuropsychopharmacology 4: $17-26$.

McGregor C, Srisurapanont M, Jittiwutikarn J, Laobhripatr S, Wongtan T, White JM (2005). The nature, time course and severity of methamphetamine withdrawal. Addiction 100: $1320-1329$

McMahon LR, Wellman PJ (1996). Effects of systemic phenylpropanolamine and fenfluramine on serotonin activity within rat paraventricular hypothalamus. Physiol Behav 59: 63-69.

Miller DK, Nation JR, Wellman PJ (1999). Sensitization of anorexia and locomotion induced by chronic administration of ephedrine in rats. Life Sci 65: 501-511.

Mittleman G, Rushing PA, Winders SE (1993). Effects of phenylpropanolamine on regulatory and nonregulatory ingestion in adult rats. Physiol Behav 54: 515-521.

Niculescu M, Ehrlich ME, Unterwald EM (2005). Age-specific behavioral responses to psychostimulants in mice. Pharmacol Biochem Behav 82: 280-288.

Olausson P, Engel JA, Soderpalm B (2000). Effects of serotonergic manipulations on the behavioral sensitization and disinhibition associated with repeated amphetamine treatment. Pharmacol Biochem Behav 66: 211-220.

Paine TA, Jackman SL, Olmstead MC (2002). Cocaine-induced anxiety: alleviation by diazepam, but not buspirone, dimenhydrinate or diphenhydramine. Behav Pharmacol 13: 511-523.

Patrick KS, Kilts CD, Breese GR (1981). Synthesis and pharmacology of hydroxylated metabolites of methylphenidate. J Med Chem 24: 1237-1240.

Pennartz CM, Groenewegen HJ, Lopes da Silva FH (1994). The nucleus accumbens as a complex of functionally distinct neuronal ensembles: an integration of behavioural, electrophysiological and anatomical data. Prog Neurobiol 42: 719-761.

Pert A, Post R, Weiss SR (1990). Conditioning as a critical determinant of sensitization induced by psychomotor stimulants. NIDA Res Monogr 97: 208-241. 
Pierce RC, Bell K, Duffy P, Kalivas PW (1996). Repeated cocaine augments excitatory amino acid transmission in the nucleus accumbens only in rats having developed behavioral sensitization. J Neurosci 16: 1550-1560.

Post RM, Kopanda RT (1976). Cocaine, kindling, and psychosis. Am J Psychiatry 133: 627-634.

Raven MA, Necessary BD, Danluck DA, Ettenberg A (2000). Comparison of the reinforcing and anxiogenic effects of intravenous cocaine and cocaethylene. Exp Clin Psychopharmacol 8: 117-124.

Roberts DC (2005). Preclinical evidence for GABAB agonists as a pharmacotherapy for cocaine addiction. Physiol Behav 86: 18-20.

Robinson TE, Berridge KC (2001). Incentive-sensitization and addiction. Addiction 96: 103-114.

Robinson TE, Browman KE, Crombag HS, Badiani A (1998). Modulation of the induction or expression of psychostimulant sensitization by the circumstances surrounding drug administration. Neurosci Biobehav Rev 22: 347-354.

Rushing PA, Winders SE, Mittleman G (1993). Effects of phenylpropanolamine infusion and withdrawal on body weight and dietary composition in male and female rats. Physiol Behav 54: $523-530$.

Scheel-Kruger J, Cools AR, van Wel PM (1977). Muscimol a GABAagonist injected into the nucleus accumbens increases apomorphine stereotypy and decreases the motility. Life Sci 21: $1697-1702$.

Segal DS, Kuczenski R (1997). An escalating dose 'binge' model of amphetamine psychosis: behavioral and neurochemical characteristics. J Neurosci 17: 2551-2566.

Sherer MA (1988). Intravenous cocaine: psychiatric effects, biological mechanisms. Biol Psychiatry 24: 865-885.

Shimosato K, Ohkuma S (2000). Simultaneous monitoring of conditioned place preference and locomotor sensitization following repeated administration of cocaine and methamphetamine. Pharmacol Biochem Behav 66: 285-292.

Smith AJ, Bolam JP (1990). The neural network of the basal ganglia as revealed by the study of synaptic connections of identified neurons. Trends Neurosci 13: 259-265.

Solanto MV (1998). Neuropsychopharmacological mechanisms of stimulant drug action in attention-deficit hyperactivity disorder: a review and integration. Behav Brain Res 94: 127-152.

Spear LP, Brake SC (1983). Periadolescence: age-dependent behavior and psychopharmacological responsivity in rats. Dev Psychobiol 16: 83-109.

Spinella M (2003). Relationship between drug use and prefrontalassociated traits. Addict Biol 8: 67-74.

Steketee JD, Beyer CE (2005). Injections of baclofen into the ventral medial prefrontal cortex block the initiation, but not the expression, of cocaine sensitization in rats. Psychopharmacology 180: $352-358$.

Szumlinski KK, Abernathy KE, Oleson EB, Klugmann M, Lominac $\mathrm{KD}, \mathrm{He} \mathrm{D}-\mathrm{Y}$ et al (2006). Homer isoforms differentially regulate cocaine-induced neuroplasticity. Neuropsychopharmacology 31: 768-777.

Szumlinski KK, Allan M, Talangbayan H, Tracey A, Szechtman H (1997). Locomotor sensitization to quinpirole: environmentmodulated increase in efficacy and context-dependent increase in potency. Psychopharmacology 134: 193-200.

Szumlinski KK, Dehoff MH, Kang SH, Frys KA, Lominac KD, Rohrer J et al (2004a). Homer proteins regulate vulnerability to cocaine. Neuron 43: 401-413.

Szumlinski KK, Frys KA, Kalivas PW (2004b). Dissociable roles for the dorsal and median raphe in the facilitatory effect of 5-HT1A receptor stimulation upon cocaine-induced locomotion and sensitization. Neuropsychopharmacology 29: 1675-1687.
Szumlinski KK, Haskew RE, Balogun MY, Maisonneuve IM, Glick SD (2000a). Iboga compounds reverse the behavioural disinhibiting and corticosterone effects of acute methamphetamine: implications for their antiaddictive properties. Pharmacol Biochem Behav 69: 485-491.

Szumlinski KK, Lominac KD, Frys KA, Middaugh LD (2005a). Genetic variation in heroin-induced changes in behaviour: effects of B6 strain dose on conditioned reward and locomotor sensitization. Genes Brain Behav 4: 324-336.

Szumlinski KK, Lominac KD, Kleschen M, Oleson EB, Dehoff M et al (2005b). Behavioural and neurochemical phenotyping of Homer1 mutant mice: possible implications for schizophrenia. Genes Brain Behav 4: 273-288.

Szumlinski KK, Lominac KD, Oleson EB, Walker JK, Mason A, Dehoff $\mathrm{MH}$ et al (2005c). Homer2 is necessary for ethanolinduced neuroplasticity. J Neurosci 25: 7054-7061.

Szumlinski KK, Maisonneuve IM, Glick SD (2000b). Differential effects of ibogaine on behavioural and dopamine sensitization to cocaine. Eur J Pharmacol 398: 259-262.

Szumlinski KK, McCafferty CA, Maisonneuve IM, Glick SD (2000c). Interactions between 18-methoxycoronaridine (18MC) and cocaine: dissociation of behavioural and neurochemical sensitization. Brain Res 871: 245-258.

Szumlinski KK, Price KL, Frys KA, Middaugh LD (2002). Unconditioned and conditioned factors contribute to the 'reinstatement' of cocaine place conditioning following extinction in C57BL/6 mice. Behav Brain Res 136: 151-160.

Tang XC, McFarland K, Cagle S, Kalivas PW (2005). Cocaineinduced reinstatement requires endogenous stimulation of $\mu$ opioid receptors in ventral pallidum. J Neurosci 25: 4512-4520.

Thiébot M-H, Kloczko J, Chermat R, Puech AJ, Soubri P, Simon P (1981). Enhancement of cocaine-induced hyperactivity in mice by benzodiazepines: evidence for an interaction of GABAergic processes with catecholaminergic neurons? Eur J Pharmacol 76: 335-343.

Torres-Reveron A, Dow-Edwards DL (2005). Repeated administration of methylphenidate in young, adolescent, and mature rats affects the response to cocaine later in adulthood. Psychopharmacology 181: 38-47.

Vanderschuren LJ, Beemster P, Schoffelmeer AN (2003). On the role of noradrenaline in psychostimulant-induced psychomotor activity and sensitization. Psychopharmacology 169: 176-185.

Vanderschuren LJ, Kalivas PW (2000). Alterations in dopaminergic and glutamatergic transmission in the induction and expression of behavioral sensitization: a critical review of preclinical studies. Psychopharmacology 151: 99-120.

Wellman PJ (1990). The pharmacology of the anorexic effect of phenylpropanolamine. Drugs Exp Clin Res 16: 487-495.

Wellman PJ, Shelton K, Schenk S (1989). Self-administration of phenylpropanolamine (PPA) by rats previously trained to self-administer amphetamine. Pharmacol Biochem Behav 34: 187-191.

Woolverton WL, Johanson CE, de la Garza R, Ellis S, Seiden LS, Schuster CR (1986). Behavioral and neurochemical evaluation of phenylpropanolamine. J Pharmacol Exp Ther 237: 926-930.

Xi ZX, Ramamoorthy S, Shen H, Lake R, Samuvel DJ, Kalivas PW (2003). GABA transmission in the nucleus accumbens is altered after withdrawal from repeated cocaine. $J$ Neurosci 23: 3498-3505.

Zhang XY, Kehoe P, Kosten TA (2006). Neonatal isolation alters estrous cycle effects on ventral striatal extracellular monoamine levels. Prog Neuropsychopharmacol Biol Psychiatry 30: 504-511.

Zito JM, Safer DJ, dosReis S, Gardner JF, Boles M, Lynch F (2000). Trends in the prescribing of psychotropic medication to preschoolers. J Amer Med Assoc 283: 1025-1030. 